\title{
FLEXURAL BEHAVIOR OF REINFORCED CONCRETE BEAMS WITH NANO-METAKAOLIN
}

\author{
Ehab M. Lotfy ${ }^{1}$ and Manar Abdelshakor ${ }^{2}$
}

\begin{abstract}
Concrete is the most broadly utilized construction material in structural building because of its high structural strength and stability, using strength and high performance concrete has been expanding all through the world. Among the different techniques used to improve the strength and performance of concrete, utilization of Cement Replacement Material (CRM) like Meta-kaolin is a generally new approach. The understanding of fracture mechanism of reinforced concrete (RC) structure is vital and under this study its focusing to crack and deflection behavior for RC beam under static loading. An experimental investigation has been carried out on 7-RC beam to investigate the behavior of reinforced concrete beams with $10 \%$ of Nano-Metakaolin in flexural to study effect of utilizing Nano-Metakaolin, effect of flexural reinforcement ratios, effect of compression reinforcement ratios and effect of characteristic strength of concrete.

It is found that partial replacement of cement with Nano -Metakaolin has a greater influence on the tested beams by $122,107,107 \& 125 \%$ for initial crack, ultimate load, maximum defection and toughness, with minimum flexural reinforcement ratio $1.29 \%$, and minimum compression reinforcement ratio 0.44 .

Keywords- Flexural Strength, Reinforced Concrete, Nano-Metakaolin (MK)
\end{abstract}

\section{INTRODUCTION}

Concrete is one of most broadly utilized construction materials in the planet, with two billion tons set worldwide every year. It is appealing in numerous applications because it offers considerable strength at a relatively low cost. Concrete can generally be produced of locally available constituents, can be cast into a wide variety of structural configurations, and requires minimal maintenance during service. Enormous reviews have been done to investigate the likelihood of using an extensive variety of materials as partial replacement material for cement in the preparation of concrete. The utilization of supplementary cementations material in the preparation of concrete may result in major saving of energy, cost and reduction in environmental pollution. It is additionally enhances workability, strength, durability and chemical resistance of concrete. There are number of supplementary cementations material are accessible, for example, fly ash, metakaolin, silica fume, slag cement, rice husk, coconut shell etc.

The utilization of high strength concrete in structure application has been expanding around the world. A couple of years prior, a characteristic compressive strength of $40 \mathrm{~N} / \mathrm{mm}^{2}$ would have been viewed as high strength concrete, yet now it was turned out to be typical wonders. These days, concrete with a 28 days curing and has characteristic cube strength of $60 \mathrm{~N} / \mathrm{mm}^{2}$ or more will be considered as a high strength concrete. The accomplishment of such high strength concrete has been conceivable fundamentally through the introduction of materials such as Metakaolin. Metakaolin is the latest mineral to be commercially introduced to the concrete construction industry.

There are a few points of interest of fusing Metakaolin to produce high strength for high rise building. These include reductions in member thickness resulting in reduced foundation loads, increased rentable areas and smaller structural element, as well as high early strength development of concrete which allows early stripping of formwork, therefore accelerating concrete construction. The raw material contribution to the manufacture of Metakaolin (MK) is kaolin clay. Kaolin is a fine, white, clay mineral that has been generally utilized in the manufacture of porcelain. It is

\footnotetext{
${ }^{1}$ Civil Engineering Department, Associate Professor Faculty of Engineering, Suez Canal University, Egypt

${ }^{2}$ Civil Engineering Department, Lecture Faculty of Engineering, Suez Canal University, Egypt
} 
believed that the term kaolin is derived from the Chinese Kaoling, which translates loosely to white hill and has been related to the name of a mountain in China that yielded the first kaolins that were sent to Europe. Kaolinite is the mineralogical term that is applicable to kaolin clays. Kaolinite is defined as a typical mineral, hydrated aluminum disilicate, $\mathrm{Al}_{2} \mathrm{Si}_{2} \mathrm{O}_{5}(\mathrm{OH})$.

Metakaolin (MK) is a supplementary cementing material that complies with ASTM C 618, Class N[1] pozzolan specifications and it is considered as a pozzolanic material which is without direct cementitious value, yet will, within the presence of moisture, reacts chemically with calcium hydroxide $(\mathrm{CH})$ to form compounds possessing cementitious properties. It is acquired by the calcinations of kaolin at a temperature extending in the vicinity of $500^{\circ} \mathrm{C}$ and $800^{\circ} \mathrm{C}$. The material is a fine, white, clay mineral MK has been known to enhance strength and porerefinement at relatively early ages [2].

\section{PREVIOUS RESEARCH}

P. Dinakar et.al. [3], by utilizing Metakaolin and cement with low water/binder ratio of 0.3 , high performance concretes can be produced. From results it can be realized that Cube Compressive strength, Splitting tensile strengths and elastic modulus results shown higher values at 10\% replacement of cement by Metakaolin.

Nova John [4], the outcomes appears by the partial replacement of cement with Metakaolin helps in achieving high strengths in concrete. At 15\% replacement of cement with Metakaolin content improves the strength characteristics such as of Cube Compressive Strength, Split Tensile Strength and Flexural Strength.

K.Srinivasu et.al.[5], Better Outcomes are accomplished by adding mineral admixtures like Metakaolin with silica fume, flyash and steel fibers in HPC. Water absorption is improved by use of Metakaolin in concrete which increases density.

M. Nazeer, R. Arun Kumar [6], the impact resistance of both binary blended and ternary blended mixes shows remarkable improvement compared to concrete mix with cement as the only binder.

\section{EXPERIMENTAL PROGRAM}

Materials and Methods

A) Materials

1. Cement

The cement utilized during the investigation is 52- grade Ordinary Portland Cement. The cement was purchased from single source. The specific gravity of the above cement was 3.15 and it is conforming to Egyptian Standard Specification [7].

\section{Aggregates}

Natural river sand was used as fine aggregate and broken granite stones of size $20 \mathrm{~mm}$ was used as coarse aggregate. Fine aggregates confirm to Zone II grading with specific gravity 2.64 and bulk density of $1560 \mathrm{~kg} / \mathrm{m}^{3} \mathrm{respectively}$. The specific gravity of coarse aggregate was 2.83 .

3. Water

Potable water available in laboratory was used in this investigation for making concrete.

\section{Nano - Metakaolin}

Metakaolin is a dehydroxylated form of the clay mineral kaolinite. Metakaolin was ground in a heat-treated at $800^{\circ}$ $\mathrm{C}$ for $2 \mathrm{hr}$ high speed ball grinding mill and it was reduced to nano scale, and investigated using SEM Quanta FEG 250 at Suez and Sinai Metallurgical and Materials Research Center of Scientific Excellence (SSMMR-CSE), Suez University, Suez, Egypt, Fig. 1 a and b respectively.

It was observed that the particles sizes were decreased after heat-treatment and also the layered were reached to a nano-scale. It was reported that the nano-layer thickness and the Sub micron layer is more useful for concrete properties 


\section{Object and Scope:}

The experimental program included testing of 7-RC beams to investigate the behavior of reinforced concrete beams with Nano-Metakaolin in flexural to study

I. Effect of using Nano-Metakaolin.

II. Effect of flexural reinforcement ratios.

III. Effect of compression reinforcement ratios.

IV. Effect of characteristic strength of concrete.

Description of the tested beams:

This study involved testing of seven concrete beams; two-span concrete beams with rectangular cross-sections of $100 * 200 \mathrm{~mm}$, total length of $2050 \mathrm{~mm}$ and tested length of $1750 \mathrm{~mm}$ were tested. Table (1) shows the details of tested beams, All beams were divided into four groups of different reinforced concrete beams; group one contains control beam with reinforcement $(A s=2 \Phi 12 \mathrm{~mm})$ and $\left(A S^{\prime}=2 \Phi 8 \mathrm{~mm}\right)$ and $\varnothing 6 \mathrm{~mm} @ 20 \mathrm{~cm}$ as shear reinforcement. Group two contains three beams with characteristic strength 25Mpa and 10\% Nano-Metakaolin and different ratios of flexural reinforcement as shown in table (1). Group three contains two beams with characteristic strength 25Mpa and $10 \%$ Nano-Metakaolin and different ratios of compression reinforcement as shown in table (1). Group four contains a beam with characteristic strength $35 \mathrm{Mpa}$ and $10 \%$ Nano-Metakaolin and reinforcement $(\mathrm{As}=2 \Phi 12 \mathrm{~mm})$ and $\left(\mathrm{AS}^{\prime}=2 \Phi 8 \mathrm{~mm}\right)$ and $\varnothing 6 \mathrm{~mm} @ 20 \mathrm{~cm}$ shear reinforcement as shown in figs. (2-5).

Table (1) Details of tested beams.

\begin{tabular}{|c|c|c|c|c|c|c|c|c|c|}
\hline \multirow{2}{*}{ Group No } & \multirow{2}{*}{ Beam No } & \multicolumn{2}{|c|}{ Dim. (mm) } & \multirow{2}{*}{$\begin{array}{l}\text { Mpa } \\
\text { Mpa }\end{array}$} & \multicolumn{4}{|c|}{ Reinforcement } & \multirow{2}{*}{$\begin{array}{l}\text { Nano-Meta } \\
\text { kaolin }(\%)\end{array}$} \\
\hline & & width & depth & & $\begin{array}{l}\text { Flex. } \\
\text { Rfmt }\end{array}$ & $\begin{array}{l}\text { Flex. } \\
\text { Rfmt Ratio (\%) }\end{array}$ & $\begin{array}{l}\text { Comp. } \\
\text { Rfmt }\end{array}$ & $\boldsymbol{\alpha}=\mathbf{A}_{\mathbf{s}}{ }^{\prime} / \mathbf{A}_{\mathbf{s}}$ & \\
\hline G1 & CB1 & \multirow{7}{*}{100} & \multirow{7}{*}{200} & \multirow{6}{*}{25} & $2 \Phi 12$ & 1.29 & $2 \Phi 8$ & 0.44 & - \\
\hline \multirow{3}{*}{ G2 } & B2 & & & & $2 \Phi 10$ & 0.89 & $2 \Phi 8$ & 0.64 & 10 \\
\hline & B3 & & & & $2 \Phi 12$ & 1.29 & $2 \Phi 8$ & 0.44 & 10 \\
\hline & B4 & & & & $3 \Phi 12$ & 1.93 & $2 \Phi 8$ & 0.296 & 10 \\
\hline \multirow{2}{*}{ G3 } & B5 & & & & $2 \Phi 12$ & 1.29 & $2 \Phi 6$ & 0.25 & 10 \\
\hline & B6 & & & & $2 \Phi 12$ & 1.29 & $2 \Phi 10$ & 0.69 & 10 \\
\hline G4 & B7 & & & 35 & $2 \Phi 12$ & 1.29 & $2 \Phi 8$ & 0.44 & 10 \\
\hline
\end{tabular}


Fig.2 Details of reinforcement and dimensions in $\mathrm{mm}$ for group 1

Fig.3 Details of reinforcement and dimensions in mm for group 2

Fig.4 Details of reinforcement and dimensions in $\mathrm{mm}$ for group 3

Fig.5 Details of reinforcement and dimensions in $\mathrm{mm}$ for group 4 
Loading Arrangement:

The load was applied by universal testing machine of $2000 \mathrm{KN}$. Full capacity through a loading plate and a spreader beam to give two-point loading $(60 \mathrm{~cm})$ as shown in Fig. 6

Fig.6 Loading Arrangement of tested beams

\section{RESULTS AND DISCUSSION}

Table 2 demonstrates the actual $f_{\text {cu }}$, cracking load, ultimate load, maximum deflection of tested specimens and type of failure.

Table 2. The results of tested beams

\begin{tabular}{|c|c|c|c|c|c|c|c|c|c|}
\hline Group No. & Beam No. & $\begin{array}{l}\text { Actual } \\
\mathbf{f}_{\text {cu }}(\mathbf{M p a})\end{array}$ & $\begin{array}{l}\text { Cracking } \\
\text { Load }(\mathbf{k N})\end{array}$ & $\begin{array}{l}\text { Ultimate } \\
(\mathbf{k N})\end{array}$ & Load & $\begin{array}{l}\text { Max. } \\
(\mathbf{m m})\end{array}$ & Deflection & $\begin{array}{l}\text { Toughness } \\
(\mathrm{kN} . \mathrm{mm})\end{array}$ & $\begin{array}{l}\text { Type of } \\
\text { failure }\end{array}$ \\
\hline G1 & CB1 & 27 & 18 & 53 & & 28 & & 1081 & flexural-shear \\
\hline \multirow{3}{*}{ G2 } & B2 & 31 & 14 & 37.7 & & 28.8 & & 876 & flexural-shear \\
\hline & B3 & 30.5 & 22 & 56.7 & & 30 & & 1353 & flexural-shear \\
\hline & B4 & 30 & 23 & 70.6 & & 32.5 & & 1588 & shear \\
\hline \multirow{2}{*}{ G3 } & B5 & 30.5 & 10 & 28.4 & & 23.2 & & 163 & shear \\
\hline & B6 & 31 & 22 & 57.2 & & 48.5 & & 2425 & flexural-shear \\
\hline G4 & B7 & 39 & 25 & 62 & & 32 & & 1524 & shear \\
\hline
\end{tabular}

1. Mode of failure

All tested beams exhibited a conventional failure in which the beam failed through yielding of the steel reinforcement followed by crushing in concrete by large strains. Fig. 7 shows the crack patterns of tested beams. 
From table 2, it can be seen that, initial cracking load of B3 with $10 \%$ of Nano-Metakaolin to CB1 is $122 \%$. Initial cracking load of B2, B4 with different flexural reinforcement ratios $0.89,1.93 \%$ to B3 with flexural reinforcement ratios $1.29 \%$ are 64 and $105 \%$ respectively.

Initial cracking load of B5, B6 with different compression reinforcement ratios $0.25,0.69$ to B3 with compression reinforcement ratios 0.44 are $45 \%$ and $100 \%$ respectively.

Initial cracking load of B7; with 35 Mpa characteristic strength to B3; with 25 Mpa characteristic strength is $114 \%$.
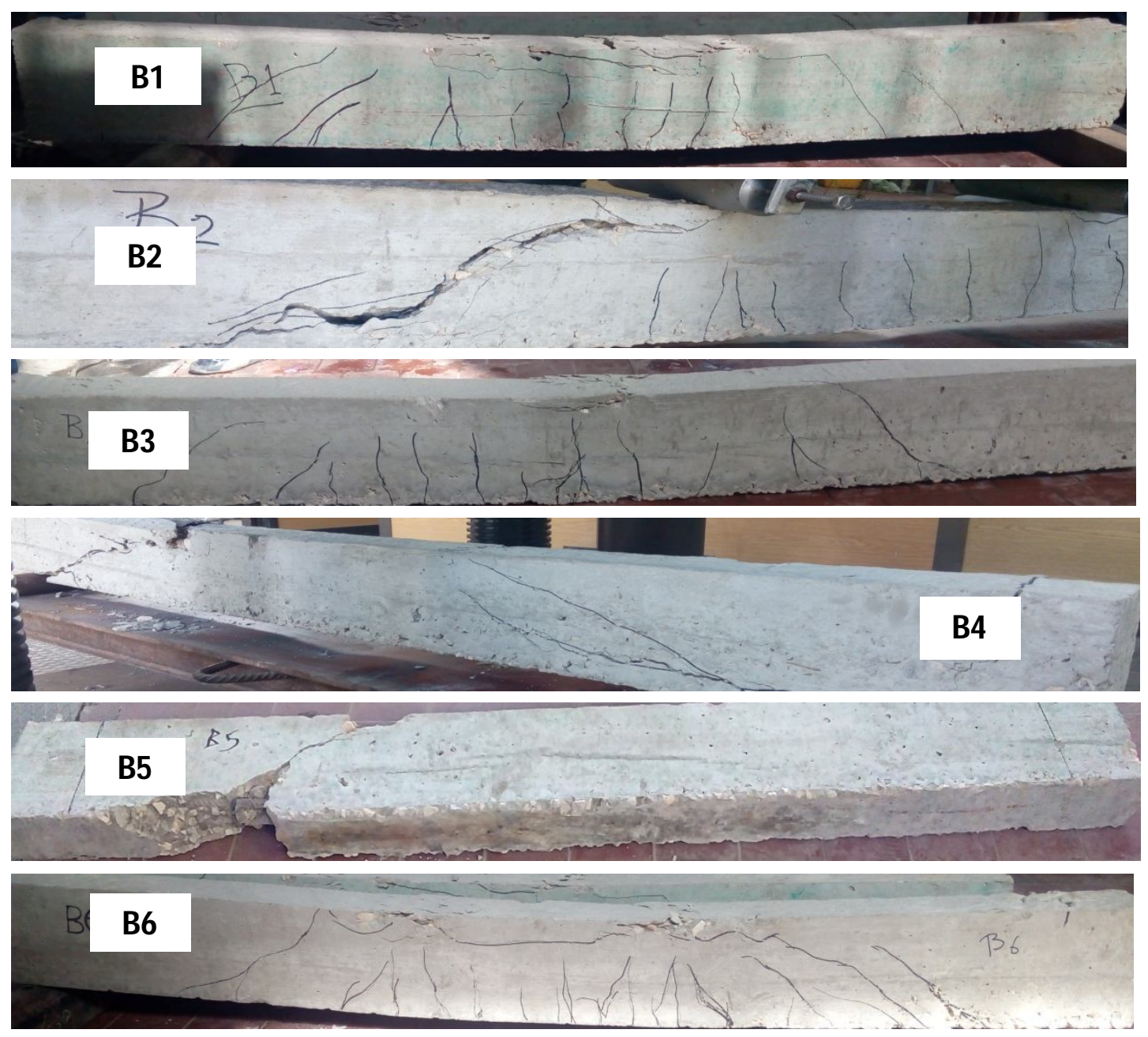

\section{B7}

Fig.7 Crack Patterns of Tested Beams

\section{Load-deflection relationship}

Load versus mid-span deflection relationships are shown in Figs. 8-11, while table 2 summarizes the structural test results. The ultimate load was defined as the maximum recorded load during testing of each beams.

From table 2, it can be seen that, ultimate load and maximum deflection of B3 with $10 \%$ of Nano-Metakaolin to CB1 are $107 \%$ and $107 \%$ respectively. Ultimate load and maximum deflection of B2, B4 with different flexural reinforcement ratios $0.89,1.93 \%$ to $\mathrm{B} 3$ with flexural reinforcement ratios $1.29 \%$ are $(66 \%, 125 \%)$ and $(96 \%, 108 \%)$ respectively. Ultimate load and maximum deflection of B5, B6 with different compression reinforcement ratios $0.25,0.69$ to $\mathrm{B} 3$ with compression reinforcement ratios 0.44 are $(50 \%, 101 \%)$ and $(77 \%$, 162\%) respectively. Ultimate load and maximum deflection of B7; with $35 \mathrm{Mpa}$ characteristic strength to B3; with 25Mpa characteristic strength is $109 \%$ and $107 \%$ respectively. 
Fig.8 Load-Deflection curve of B1 \& B3

Fig.9 Load-Deflection curve of B2, B3 \& B4

Fig.10 Load-Deflection curve of B3, B5 \& B6 
Fig.11 Load-Deflection curve of B3\& B7

\section{EVALUATION OF TEST RESULTS}

1. Effect of using Nano-Metakaolin

Fig. 12 shows the relationship of initial crack, ultimate load, maximum defection and toughness of tested beams CB1 (control beam) and B3 with 10\% of Nano -Metakaolin, where using Nano -Metakaolin with 10\% increase initial crack, ultimate load, maximum defection and toughness of tested beams by 122,107,107 and $125 \%$ respectively.

Using Nano-Metakaolin with $10 \%$ enhancing the properties of used concrete by $122,107,107 \& 125 \%$ for initial crack, ultimate load, maximum defection and toughness of tested beams

Fig.12 Initial crack, ultimate load, maximum defection and toughness of tested beams CB1\& B3

2. Effect of flexural reinforcement ratios.

Fig. 13 shows the relationship of flexural reinforcement ration of B2, B3 and B4 with different flexural reinforcement ratios $0.89,1.29 \& 1.93 \%$ and their percentage values of initial crack, ultimate load, maximum defection and toughness of tested beams to values of B3.

Increasing flexural reinforcement ration from $0.89 \%$ to $1.29 \%$ increase initial crack, ultimate load, maximum defection and toughness of tested beams by $157,150,105$ and $154 \%$ respectively, whereas increasing flexural reinforcement ration from $1.29 \%$ to $1.93 \%$ increase initial crack, ultimate load, maximum defection and toughness of tested beams by $105,125,108$ and $117 \%$ respectively. 
Increasing flexural reinforcement ration up to $1.29 \%$ has a significant effect on initial crack, ultimate load, maximum defection and toughness of tested beams so it is recommended that minimum flexural reinforcement ratio $1.29 \%$.

Fig.13 Flexural reinforcement ratios and their percentage values with B3 ( $\rho=1.29 \%)$

\section{Effect of compression reinforcement ratios.}

Fig.14 shows the relationship of compression reinforcement ration of B5, B3 and B6 with different flexural compression ratios $0.25,0.44 \& 0.69$ and their percentage values of initial crack, ultimate load, maximum defection and toughness of tested beams to values of B3.

Increasing compression reinforcement ration from 0.25 to 0.44 increase initial crack, ultimate load, maximum defection and toughness of tested beams by $220 \%, 199 \%, 129 \%$ and $830 \%$ respectively, whereas increasing flexural reinforcement ration from 0.44 to 0.69 increase initial crack, ultimate load, maximum defection and toughness of tested beams by $100 \%, 101 \%, 162 \%$ and $179 \%$ respectively.

Increasing compression reinforcement ration up to 0.44 has a significant effect on initial crack, ultimate load, maximum defection and toughness of tested beams so it is recommended that minimum compression reinforcement ratio 0.44 


\section{Effect of characteristic strength of concrete.}

Fig. 15 shows the relationship of initial crack, ultimate load, maximum defection and toughness of tested beams B7; with $35 \mathrm{Mpa}$ characteristic strength to B3; with $25 \mathrm{Mpa}$ characteristic strength, where using 35Mpa characteristic strength of concrete with Nano-Metakaolin with $10 \%$ increase initial crack, ultimate load, maximum defection and toughness of tested beams by $114,109,107$ and $127 \%$ respectively.

Using concrete with $35 \mathrm{Mpa}$ characteristic strength of and Nano-Metakaolin with $10 \%$ has a significant effect on the initial crack and toughness of tested beams.

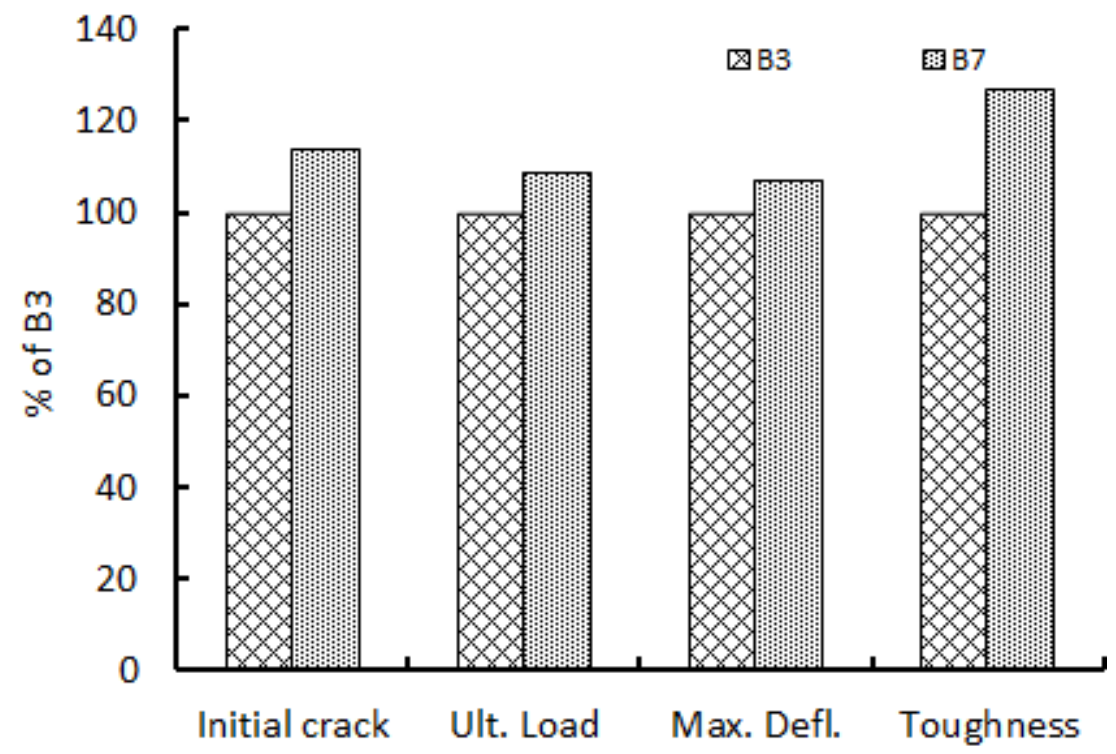

Fig.15 Initial crack, ultimate load, maximum defection and toughness of tested beams B7\& B3

\section{CONCLUSION}

Based on the experimental investigations the following conclusions are drawn:

I. Using Nano-Metakaolin with $10 \%$ has a greater influence on the tested beams by $122,107,107 \& 125 \%$ for initial crack, ultimate load, maximum defection and toughness.

II. Increasing flexural reinforcement ration up to $1.29 \%$ has a significant effect on the properties of reinforced concrete beams and it is recommended that minimum flexural reinforcement ratio $1.29 \%$.

III. Increasing compression reinforcement ration up to 0.44 has a significant effect on the properties of reinforced concrete beams and it is recommended that minimum compression reinforcement ratio 0.44 .

IV. Using concrete with 35Mpa characteristic strength of and $10 \%$ of Nano-Metakaolin has a significant effect on the initial crack and toughness of tested beams.

\section{REFERENCES}

[1] ASTM C 618, Class N, Annual Book of ASTM Standards, Vol. 04.02.

[2] Nalleni Sreeharsha, K.V.Ramana "Study On the Strength Characteristics of Concrete with Partial Replacement of Cement by Zeolite and Metakaolin" International Journal of Innovative Research in Science, Engineering and Technology, Vol. 5, Issue 12, December 2016, 20363-20371 pp

[3] Dinakar, Pradosh K. Sahoo, and G. Sriram, "Effect of Metakaolin Content on the Properties of High Strength Concrete" IJCSM, Volume 7,no3, pp215-223 September 2013.

[4] Nova John, "Strength Properties of Metakaolin Admixed Concrete" IJSRP, Vol. 3, Issue6, June 2013, 1-7 PP.

[5] Krishna Rao B, A.V.S.Sai. Kumar, "A Study on Strength of Concrete With Partial Replacement Of Cement With Quarry Dust And Metakaolin" IJIRSET, Vol. 3 issue 3 mar 2014, pp-14697-14701.

[6] M. Nazeer, R. Arun Kumar, "Strength Studies on Metakaolin Blended High-Volume Fly Ash Concrete" IJEAT, Vol. 3, issue 6 August 2014, pp176-179.

[7] Egyptian Standard Specification, 2002 